\title{
Casca de banana: uma possivel fonte de infecção no tratamento de fissuras mamilares
}

\author{
Banana peel: a possible source of infection in the treatment of nipple fissures
}

Franz Reis Novak ${ }^{1}$, João Aprígio Guerra de Almeida ${ }^{2}$, Rosana de Souza e Silva ${ }^{3}$

\section{Resumo}

Objetivo: o presente trabalho foi desenvolvido com o objetivo de estudar a microbiota da casca de banana prata, comercializada na cidade do Rio de Janeiro, tentando correlacioná-la com a possibilidade de que seja uma fonte de infecção para a mulher que a utiliza como terapia para fissuras mamilares.

Métodos: foram estudados, em 20 amostras de casca de banana, os seguintes microrganismos: mesófilos, coliformes totais, coliformes fecais, Pseudomonas aeruginosa, lipolíticos, proteolíticos, bolores e leveduras, bactérias lácticas e estafilococos coagulase-positiva.

Resultados: as análises microbiológicas revelaram a ocorrência de diversos grupos clássicos de microrganismos. A distribuição percentual dos resultados positivos nas amostras de casca de banana, em função das contagens, foram: mesófilos, 100\%; coliformes totais, $20 \%$; estafilococos coagulase-positiva, $25 \%$; bolores e leveduras, $30 \%$; proteolíticos, $70 \%$; lipolíticos, $30 \%$ e bactérias lácticas, 95\%. Coliformes fecais e Pseudomonas aeruginosa não foram isolados.

Conclusão: a avaliação conjunta dos resultados revela a presença de microrganismos potencialmente patogênicos em níveis capazes de comprometer a qualidade microbiológica da casca de banana. A sua aplicação sobre fissuras mamilares para o tratamento destas pode favorecer o início de um processo infeccioso.

J Pediatr (Rio J) 2003;79(3):221-6: amamentação, leite humano, banana.

\begin{abstract}
Objective: the objective of the present investigation is to study the microbiology of banana peel being sold in the city of Rio de Janeiro, in an attempt to determine the possibility that the peel may represent a source of infection for women who use it to treat nipple fissures.
\end{abstract}

Methods: the following microorganisms were studied in 20 banana peel samples: mesophiles, total coliforms, fecal coliforms, Pseudomonas aeruginosa, lipolytic and proteolytic microorganisms, molds and yeasts, lactic bacteria, and coagulase-positive staphylococcus.

Results: the microbiological analyses revealed the occurrence of several typical groups of microorganisms, with the following distribution of positive results being detected in banana peel samples: mesophiles, 100\%; total coliforms, 20\%; coagulase-positive staphylococcus, 25\%; molds and yeasts, 30\%; proteolytic microorganisms, 70\%; lipolytic microorganisms, 30\%, and lactic bacteria, 95\%. Fecal coliforms and Pseudomonas aeruginosa were not isolated.

Conclusion: the results show the presence of potentially pathogenic microorganisms in levels which could compromise the microbiological quality of the banana peel. Its use for the treatment of nipple fissures can initiate an infectious process.

J Pediatr (Rio J) 2003;79(3):221-6: breast-feeding, human milk, banana.

1. Doutor em Microbiologia. Professor nos Cursos de Mestrado e Doutorado em Saúde da Mulher e da Criança. Membro da equipe do Banco de Leite Humano do Instituto Fernandes Figueira-IFF/Fundação Oswaldo Cruz.

2. Doutor em Saúde Pública. Professor nos Cursos de Mestrado e Doutorado em Saúde da Mulher e da Criança. Chefe do Banco de Leite Humano do IFF.

3. Estudante do Programa de Vocação Científica do IFF/Fundação Oswaldo Cruz.

Artigo submetido em 23.09.02, aceito em 12.03.03. 


\section{Introdução}

$\mathrm{O}$ ato de amamentar traz inúmeras vantagens para a nutriz, como involução mais rápida do útero, economia no orçamento familiar, satisfação emocional e melhor relacionamento afetivo entre mãe e filho ${ }^{1}$. A produção do leite humano (LH) tem início durante a gestação, e se estabelece mais rapidamente quanto mais precoce for o contato entre a mãe e o bebê².

Atendendo às especificidades da maturidade orgânica do receptor, o LH é produzido com características de composição nutricional e imunológica muito específicas ${ }^{3}$. É o alimento mais indicado para a sobrevivência e o desenvolvimento da criança, pois exerce o duplo papel de elemento de nutrição e de proteção, com interferência direta no organismo da criança, na busca do equilíbrio de sua saúde ${ }^{4}$.

Um dos obstáculos à amamentação bem-sucedida são as fissuras mamilares, provenientes principalmente de problemas no posicionamento ou na pega do bebê ao seio ${ }^{5}$. O tratamento adequado das fissuras impede a sua progressão para mastite, causa comum de interrupção da amamentação 6,7 .

De modo geral, o aparecimento de fissuras não significa a necessidade de interromper a amamentação, pois, apesar destas causarem dor, podem cicatrizar rapidamente ${ }^{8,9}$. Nesse sentido, são oferecidas algumas alternativas como o uso da raspa da parte interna da casca da banana verde, colocada sobre o mamilo ${ }^{10}$ ou o emprego direto da casca sobre as fissuras.

No sul da Índia, a banana verde é usada para tratamento de pacientes com úlcera péptica, sendo prescrita sob a forma de farinha ${ }^{11}$. Em trabalho realizado por Best et al. ${ }^{12}$, várias preparações de banana verde, utilizadas em úlceras induzidas por aspirina em ratos, demonstraram serem efetivas tanto no tratamento profilático quanto curativo. Foi demonstrado, ainda, que o fator ativo é solúvel em água e que bananas amadurecidas perdem o efeito terapêutico ${ }^{12}$.

O extrato de banana verde não só aumenta a densidade da mucosa, como também a incorporação de timidina ao DNA das células, demonstrando seu efeito sobre a multiplicação celular. $\mathrm{O}$ estudo histológico mostrou que o tratamento aumentava a proliferação das células apicais e das camadas mais profundas da mucosa, sugerindo não só o aumento da resistência contra substâncias capazes de provocar úlceras, como também de promover a cura pela indução da proliferação celular ${ }^{13}$. O componente ativo encontrado na casca de bananas verdes foi extraído e identificado como um flavonóide leucocianidina ${ }^{14}$.

Os trabalhos citados acima demonstraram a existência de substâncias cicatrizantes na banana verde, fazendo com que o tratamento popular de aplicação da casca de banana "verdulenta" em fissuras mamilares não seja apenas um mito. Apesar disso, a utilização da casca de banana na terapia de fissuras mamilares não está bem documentada na literatura científica.
Diante do exposto, o presente trabalho teve como objetivos: (1) estudar a microbiota da casca de banana prata comercializada na cidade do Rio de Janeiro; (2) estudar a redução dos contaminantes microbianos naturais, através de técnicas que pudessem ser reproduzidas pelas nutrizes.

\section{Métodos}

As amostras de banana prata "verdulentas" foram adquiridas e transportadas nas mesmas condições que os comerciantes as entregam às nutrizes, isto é, em jornal, sacos de papel ou de plástico. A aquisição de tais amostras foi realizada em 20 estabelecimentos comerciais diferentes, sendo 12 feiras livres e 8 supermercados localizados a uma distância de pelo menos $1 \mathrm{Km}$ entre si, na cidade do Rio de Janeiro, no período de janeiro a agosto de 2002, e foram analisadas no laboratório de controle de alimentos do Instituto Fernandes Figueira da Fundação Oswaldo Cruz.

As cascas a serem analisadas foram trituradas em copo de liquidificador previamente esterilizado, guardando sempre a proporção 1:10, em relação ao volume de água peptonada estéril, utilizada como diluente.

Visando obter uma ampla cobertura dos possíveis grupos de microrganismos encontrados nas cascas de banana, foram estudados os seguintes grupos de microrganismos:

Mesófilos: procedeu-se de acordo com o método descrito no Compendium of Methods of the Microbiological Examination of Foods ${ }^{15}$. Alíquotas de 1,0 $\mathrm{ml}$ do homogenato e de suas diluições decimais selecionadas foram semeadas em duplicata, pela técnica de pour plate em ágarpadrão-PCA (Merck). Após a solidificação do meio, as placas foram incubadas a $35^{\circ} \mathrm{C}$ por 48 horas. Foram contadas as colônias, e os resultados expressos em unidades formadoras de colônias (UFC), por grama de casca de banana.

Coliformes totais: determinados pela técnica do número mais provável, de acordo com o descrito no Standard Methods for the Examination of Dairy Products ${ }^{16}$. Alíquotas das diluições decimais selecionadas do homogenato foram inoculadas em série de três tubos, que continham Caldo Bile Verde Brilhante - Bile 2\% - BGBL (Merck). Os tubos foram incubados a $36 \pm 1{ }^{\circ} \mathrm{C}$ durante $24 / 48$ horas. Após a incubação, observou-se a produção de gás. O número mais provável de coliformes foi calculado com o uso da tabela de McGrady ${ }^{15}$. Os tubos positivos foram repicados com alça bacteriológica para novos tubos de BGBL e incubados a $36 \pm 1^{\circ} \mathrm{C}$ por $24 / 48$ horas, para teste de confirmação, e os resultados expressos em número mais provável por grama (NMP/g).

Coliformes fecais: procedeu-se de acordo com o descrito no Standard Methods for the Examination of Dairy Products ${ }^{16}$. Os tubos em que se confirmou a presença de coliformes totais foram repicados individualmente com 
alça bacteriológica para tubos contendo Caldo EC (Merck) e incubados a $44,5 \pm 0,1^{\circ} \mathrm{C}$ em banho-maria ultratermostático, com agitação por 24/48 horas. Após a incubação, observava-se a produção de gás, para que os resultados fossem expressos em NMP/g.

Pseudomonas aeruginosa: procedeu-se de acordo com o descrito por Thornley ${ }^{17}$. Alíquotas de $0,1 \mathrm{ml}$ das diluições selecionadas foram semeadas em duplicata, pela técnica de inóculo em superfície, com auxílio de uma alça de Drigalsky, em ágar Cetrimide (Merck) e incubadas a $37^{\circ} \mathrm{C}$ por 24 horas, para serem contadas as colônias típicas, e os resultados expressos em UFC/g de casca de banana.

Estafilococos coagulase-positiva: foi pesquisado de acordo com o método descrito no Compendium of Methods for the Examination of Foods ${ }^{15}$. Alíquotas de $0,1 \mathrm{ml}$ do homogenato e de suas diluições selecionadas foram semeadas em duplicata, pela técnica de inóculo em superfície, com auxílio de uma alça de Drigalsky, em ágar BairdParker (Merck). As placas foram incubadas a $35-37^{\circ} \mathrm{C}$ por 48 horas. Foram contadas as colônias típicas, e os resultados expressos em UFC/g.

Bolores e leveduras: procedeu-se de acordo com o método descrito por Marvin ${ }^{15}$. Alíquotas de $1,0 \mathrm{ml}$ do homogenato e de suas diluições decimais selecionadas foram semeadas pela técnica de pour plate, em ágar Dextrose Batata - BDA (Merck). Após a solidificação do meio, as placas foram incubadas a $25^{\circ} \mathrm{C}$ por cinco dias. Foram contadas as colônias, e os resultados expressos UFC/g.

Lipolíticos: foram selecionadas alíquotas de $1 \mathrm{ml}$ das diluições decimais selecionadas e semeadas em duplicatas, pela técnica de pour plate em ágar Tributirina (Merck) e incubados a $25^{\circ} \mathrm{C}$ por cinco dias ${ }^{16}$. Foram contadas as colônias características, e os resultados expressos em UFC/g.

Proteolíticos: procedeu-se de acordo com o descrito por Marth ${ }^{16}$. Alíquotas de $1,0 \mathrm{ml}$ das diluições selecionadas foram semeadas em duplicata, pela técnica do pour plate em ágar Padrão - PCA (Merck), contendo 10\% de leite desnatado. Após a solidificação do meio, as placas foram incubadas a $21 \pm 2^{\circ} \mathrm{C}$ por 72 horas. Após a incubação, verteram-se $3 \mathrm{ml}$ de solução de ácido acético a $10 \%$ v/v sobre as placas, deixando-se por um minuto, e foram contadas as colônias características, e os resultados expressos em UFC/g.

Bactérias lácticas: procedeu-se de acordo com o descrito por Lima ${ }^{18}$, utilizando-se ágar Padrão (PCA, Merck) acrescido de $0,004 \mathrm{~g}$ de púrpura de bromocresol e $0,5 \mathrm{~g}$ de lactose, por $100 \mathrm{ml}$ de meio. Com o propósito de evitar a difusão do ácido produzido pelas colônias no ágar, foi adicionado $0,2 \%$ de carbonato de cálcio. Alíquotas de 1,0 $\mathrm{ml}$ do homogenato e de suas diluições decimais selecionadas foram semeadas em duplicata, pela técnica de pour plate. As placas foram incubadas a $32^{\circ} \mathrm{C}$ por 48 horas, e as colônias circundadas por um halo amarelo foram contadas, e os resultados expressos em UFC/g.
Estudou-se ainda a redução dos microrganismos encontrados na superfície das cascas de banana através da sua imersão em álcool $96^{\circ} \mathrm{GL}$, durante 10 minutos, e pela lavagem das cascas com o detergente líder no mercado para uso doméstico, por um período de três minutos.

Com relação aos aspectos éticos, o trabalho foi conduzido de acordo com o previsto nas normas e diretrizes que regulamentam, da resolução $196 / 96^{19}$, e teve seu início após ser aprovado pelo Comitê de Ética em Pesquisa do Instituto Fernandes Figueira.

\section{Resultados}

A distribuição percentual dos resultados positivos nas amostras de casca de banana foi a seguinte: mesófilos, $100 \%$; coliformes totais, $20 \%$; estafilococos coagulasepositiva, 25\%; bolores e leveduras, $30 \%$; proteolíticos, $70 \%$; lipolíticos, $30 \%$ e bactérias lácticas, $95 \%$. Coliformes fecais e Pseudomonas aeruginosa não foram isolados em nenhuma das amostras, por isso não aparecem na Tabela 1.

Durante o estudo de redução da microbiota das cascas de banana submetidas à aplicação do álcool $96^{\circ} \mathrm{GL}$ e de detergente, observou-se uma distribuição mais homogênea dos microrganismos nas cascas analisadas. Os efeitos das técnicas empregadas para reduzir os microrganismos contaminantes das cascas de banana podem ser observados na Figura 1. Cabe ressaltar que em nenhuma das 20 amostras utilizadas neste experimento observou-se o crescimento de estafilococos coagulase-positiva.

Houve redução da carga microbiana das cascas de banana pelos procedimentos propostos (teste $t$ pareado $\mathrm{p}<0,05)^{20}$, porém não foram suficientes para eliminar os contaminantes presentes (Figura 1).

\section{Discussão}

A população de microrganismos do grupo mesófilos foi observada em $100 \%$ das amostras analisadas. Tal grupo inclui a maioria dos contaminantes presentes, dentre eles, os patogênicos, e permite uma visão geral sobre a carga microbiana existente ${ }^{15}$.

Os resultados revelaram a presença de estafilococos coagulase-positiva em 25\% (5/20) das amostras, com 100\% das contagens inferiores a $10^{3} \mathrm{UFC} / \mathrm{g}$. A maior preocupação quanto à presença deste microrganismo é que o $S$. aureus está intimamente ligado com a maioria dos episódios de mastites observados na prática clínica durante a amamentação ${ }^{15}$.

A ocorrência de bolores e leveduras foi registrada em $30 \%(6 / 20)$ das amostras, e apresentaram contagens de 1,8 $\times 10^{1}$ a $3,0 \times 10^{3} \mathrm{UFC} / \mathrm{g}$. A presença destes contaminantes está associada a condições higiênicas e sanitárias insatisfatórias na cadeia produtiva da banana analisada ${ }^{21}$. 
Tabela 1 - Distribuição dos grupos de microrganismos pesquisados em 20 amostras de cascas de banana

\begin{tabular}{lccccccc}
\hline & \multicolumn{7}{c}{ Grupos de microrganismos analisados (número de amostras) } \\
\cline { 2 - 7 } $\begin{array}{l}\text { Contagens } \\
\text { por grama) }\end{array}$ & Mesófilos & $\begin{array}{c}\text { Coliformes } \\
\text { totais }\end{array}$ & $\begin{array}{c}\text { Estafilococos } \\
\text { coag. (+) }\end{array}$ & $\begin{array}{c}\text { Bolores e } \\
\text { leveduras }\end{array}$ & Lipolíticos & Proteolíticos & $\begin{array}{c}\text { Bactérias } \\
\text { láticas }\end{array}$ \\
\hline Ausência & 0 & 16 & 15 & 14 & 12 & 6 & 1 \\
$10^{0} \mid-10^{1}$ & 2 & 2 & 1 & 1 & 2 & 0 & 0 \\
$10^{1} \mid-10^{2}$ & 1 & 1 & 3 & 3 & 5 & 12 & 16 \\
$10^{2} \mid-10^{3}$ & 8 & 1 & 1 & 2 & 1 & 2 & 3 \\
$10^{3} \mid-10^{4}$ & 9 & 0 & 0 & 0 & 0 & 0 & 0 \\
\hline
\end{tabular}

A presença de bactérias lipolíticas foi detectada em $40 \%(8 / 20)$ das amostras, com contagens que variaram de $1,3 \times 10^{1}$ até $2,7 \times 10^{2} \mathrm{UFC} / \mathrm{g}$, e a presença de microrganismos proteolíticos ocorreu em $70 \%$ (14/20) das amostras, com contagens que variaram de $1,6 \times 10^{2}$ até $1,7 \times 10^{3} \mathrm{UFC} / \mathrm{g}$. Tais resultados tornam-se preocupantes, uma vez que esses microrganismos podem se tornar oportunistas, devido a sua capacidade de multiplicação em diversos tecidos necrosados ${ }^{16}$.

A população de bactérias lácticas se fez presente em 95\% (19/20) das amostras analisadas, sendo inferior a $10^{3} \mathrm{UFC} / \mathrm{g}$ em todas as contagens realizadas. As substâncias produzidas pelas bactérias do ácido láctico na solução de continuidade podem dificultar a cicatrização ${ }^{16}$.

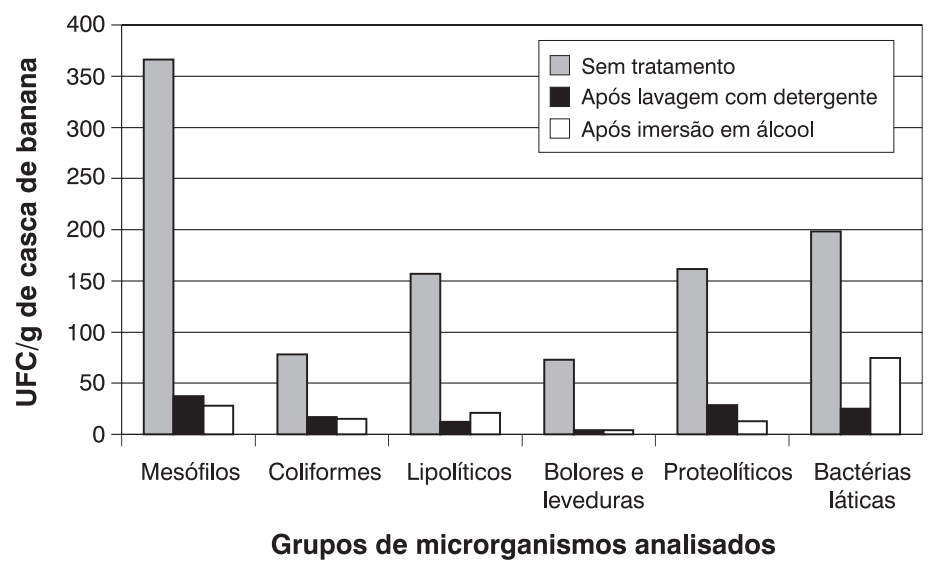

Figura 1 - Efeito do álcool $96^{\circ} \mathrm{GL}$ e do detergente comercial sobre os contaminantes encontrados na superfície das cascas de banana 
A avaliação conjunta dos resultados revela a presença de microrganismos potencialmente patogênicos, em níveis capazes de comprometer a qualidade sanitária das cascas de banana testadas. Considerando que os procedimentos utilizados para a redução da carga microbiana não foram eficientes para eliminar os contaminantes presentes - que podem iniciar um processo infeccioso, caso encontrem condições favoráveis - e que as bactérias localizadas na parte externa da casca da banana, com a manipulação, podem facilmente ser transferidas para a parte que entra em contato com as fissuras, é possível que a aplicação da casca de banana no tratamento das fissuras funcione como fonte de microrganismos capazes de iniciar um processo infeccioso. Além disso, pode haver uma reação cruzada de hipersensibilidade entre alguns compostos existentes nas bananas e o látex natural de borracha, isto é, pessoas alérgicas ao látex freqüentemente exibem reação de hipersensibilidade à banana ${ }^{22}$. $\mathrm{Na}$ experiência dos autores, diversas lactantes com si-

\section{Referências bibliográficas}

1. Almeida JAG. Amamentação: um híbrido natureza-cultura. Rio de Janeiro: Fiocruz; 1999.

2. Teruya K, Serva VB. Manejo da lactação. In: Rego JD, editor. Aleitamento materno. São Paulo: Atheneu; 2001.p.113-30.

3. Carbonare SB, Carneiro-Sampaio MMS. Composição do leite humano-aspectos imunológicos. In: Rego JD, editor. Aleitamento materno. São Paulo: Atheneu; 2001.p.83-97.

4. Nóbrega FJ. A importância nutricional do leite materno. In: Rego JD, editor. Aleitamento materno. São Paulo: Atheneu; 2001. p.59-82.

5. Cordeiro, MT. Postura, posição e pega adequadas: um bom início para a amamentação. In: Rego JD, editor. Aleitamento materno. São Paulo: Atheneu; 2001.p.131-55.

6. Devereux WP. Acute puerperal mastitis. Evaluation of its management. Am J Obstet Gynecol 1970;108:78-81.

7. Thomsen AC, Espersen T, Maigaard S. Course and treatment of milk stasis, noninfectious inflammation of the breast, and infectious mastitis in nursing women. Am J Obstet Gynecol 1984;149:492-5.

8. Bittar RE, Issler H, Zugaib M. A questão do incentivo ao aleitamento materno no pré-natal. Rev Ginecol Obstet (São Paulo) 1992;3:91-4.

9. Vinha VHP. O livro da amamentação. São Paulo: Balieiro; 1999.

10. Coordenação Nacional da Pastoral da Criança - CNBB. Aleitamento Materno [site na Internet]. Disponível: www.rebidia.org.br/dicas/maio99.html. Acessado: 12 de fevereiro de 2003. nais e sintomas de alergia na pele da mama relatam ter utilizado cascas de banana no tratamento de fissuras mamilares. No entanto, a associação entre alergia na mama e o uso de casca de banana precisa ser melhor documentada, mediante estudos com delineamento apropriado para testar esta hipótese.

Concluindo, os resultados do presente estudo alertam para a possibilidade de efeitos danosos (infecção da mama) do uso da casca de banana no tratamento de fissuras. O delineamento do estudo não permite avaliar a associação entre uso de casca de banana e infecção. Novos estudos, com delineamento específico para avaliar tal associação, são necessários, para que possam ser feitas recomendações quanto ao uso de casca de banana no tratamento das fissuras mamilares. No entanto, até que se comprove que o efeito terapêutico (teórico) da casca de banana na cicatrização das fissuras supere os riscos de seu uso, seria prudente evitar tal procedimento.

11. Dadoo RC, Khatri HL, Singla S. Comparative evaluation of gastric secretory response to banana and porridge. Indian J Med Sci 1995;49:5-8.

12. Best R, Lewis DA, Nasser N. The anti-ulcerogenic activity of the unripe plantain banana (Musa species). Br J Pharmacol 1984;82: 107-16.

13. Goel RK, Gupta S, Shankar R, Sanyal AK. Anti-ulcerogenic effect of banana powder (Musa sapientum var. paradisiaca) and its effect on mucosal resistance. J Ethnopharmacol 1986;18:33-44.

14. Lewis DA, Fields WN, Shaw GP. A natural flavonoid present in unripe plantain banana pulp (Musa sapientum L. var. paradisiaca) protects the gastric mucosa from aspirin-induced erosions. J Ethnopharmacol 1999;65:283-8.

15. Marvin LS. Compendium of methods for the microbiological examination of foods. $4^{\mathrm{a}}$ ed. Washington: APHA; 2001.

16. Marth EH. Standard methods for the examination of dairy products. 19a ed. Washington: APHA; 1992.

17. Thornley MJ. The differentiation of Pseudomonas from other gram-negative bacteria on the basis of arginine metabolism. J Appl Bacteriol 1960;23:37-52.

18. Lima MC. Efeitos de tratamentos térmicos do leite tipo $\mathrm{C}$ em grupos de microrganismos e em seu desenvolvimento durante a estocagem a diferentes temperaturas [dissertação]. Viçosa (MG): Universidade Federal de Viçosa; 1988.

19. Ministério da Saúde. Diretrizes e normas regulamentadoras de pesquisas envolvendo seres humano - Resolução 196/96 do Conselho Nacional de Saúde. Rio de Janeiro: Fiocruz; 1998.

20. Norusis MJ. Statistical Package For The Social Sciences (Version 6.0) [computer software]. Chicago, IL: SPSS; 1993. 
21. Almeida JAG. Qualidade do leite humano coletado e processado em bancos de leite [dissertação]. Viçosa (MG): Universidade Federal de Viçosa; 1986.

22. Mikkola JH, Alenius H, Kalkkinen N, Turjanmaa K, Palosuo T, Reunala TJ. Hevein-like protein domains as a possible cause for allergen cross-reactivity between latex and banana. J Allergy Clin Immunol 1998;102:1005-12.
Endereço para correspondência:

Dr. Franz Reis Novak

Banco de Leite Humano - Instituto Fernandes Figueira

Av. Rui Barbosa, 716 - Flamengo

CEP 22250-020 - Rio de Janeiro - RJ

Tel./Fax: (21) 5535669

E-mail:novak@iff.fiocruz.br 